\title{
Larger Thyroid Volume and Adequate Iodine Nutrition in Chinese Schoolchildren: Local Normative Reference Values Compared with WHO/IGN
}

\author{
Zhe Mo, Xiaoming Lou, Guangming Mao, Zhifang Wang, Wenming Zhu, \\ Zhijian Chen, and Xiaofeng Wang
}

Department of Environment and Occupational Health, Zhejiang Provincial Center for Disease Prevention and Control, Hangzhou, Zhejiang, China

Correspondence should be addressed to Xiaofeng Wang; xfwang@cdc.zj.cn

Received 24 August 2016; Revised 9 October 2016; Accepted 20 October 2016

Academic Editor: Alexander Schreiber

Copyright (C) 2016 Zhe Mo et al. This is an open access article distributed under the Creative Commons Attribution License, which permits unrestricted use, distribution, and reproduction in any medium, provided the original work is properly cited.

Objective. Thyroid volume measured by ultrasound to define goiter needs reliable local thyroid volume reference from iodinesufficient populations. The aim of this study is to explore the reference interval for normal thyroid volume in schoolchildren aged 8-10 years from Zhejiang Province, China. Methods. A probability-proportionate-to-size sampling method was applied to select a representative sample of 1213 children aged 8-10 years in Zhejiang Province to detect the thyroid volume, salt iodine, and urine iodine. Results. Median urinary iodine concentration in involved schoolchildren was $178.30(125.00) \mu \mathrm{gl} \mathrm{l}^{-1}$, with the percentage of samples less than $100 \mu \mathrm{gl}^{-1}$ as $12.69 \%$ and more than $300 \mu \mathrm{gl} \mathrm{l}^{-1}$ as $15.25 \%$. Thyroid volume was significantly correlated with age and anthropometric measurements independently of each other. The 97th percentile of thyroid volume in our study was larger generally than the new international reference. Conclusions. The iodine nutritional status in Zhejiang Province was at an adequate level. Despite some limitations in this study, we initially established the reference values for thyroid volume in 8-10-yearold schoolchildren in Zhejiang Province, China, as a local reference to be used for monitoring iodine deficiency disorders.

\section{Introduction}

Goiter prevalence in school-age children is an important indicator of iodine deficiency disorders in a population [1]. Several studies [2-4] have shown that thyroid volume measured by ultrasound is the preferred indicator in epidemiological studies and monitoring of iodine deficiency disorders. Nevertheless, thyroid volume measured by ultrasound needs reliable reference intervals for normal thyroid volume from iodine-sufficient populations.

There are many controversial issues [5-13] about defining the reference intervals for normal thyroid volume. In 2004, Zimmermann et al. [13] established the international reference intervals for thyroid volume by ultrasound adjusted for age and body surface area (BSA). These were based on 3529 schoolchildren living in areas with long-standing iodine sufficiency; age and BSA-specific upper normal limits of thyroid volume were provided by sex. These reference intervals were adopted by the World Health Organization (WHO) and Iodine Global Network (IGN) as the recommendation of thyroid volume in 2007 [1] and suggested that the populationspecific references for thyroid volume in countries with longstanding iodine sufficiency may be more accurate than a single international reference.

The Universal Salt Iodization program has been mandatory since 1994 in China; iodine nutrition indicated by median urinary iodine concentrations (MUIs) is of longstanding sufficiency $[14,15]$. However, local endemic goiter diagnostic standards [16], which ignored the growth and development factor of children, are now based on the reference published in 1993 [5].

We previously performed studies $[17,18]$ on the reference intervals for normal thyroid volume in schoolchildren of Zhejiang Province, China. However, as noted, those studies ignored the growth and development factor of children and were based on a relatively small number of observations. Few 


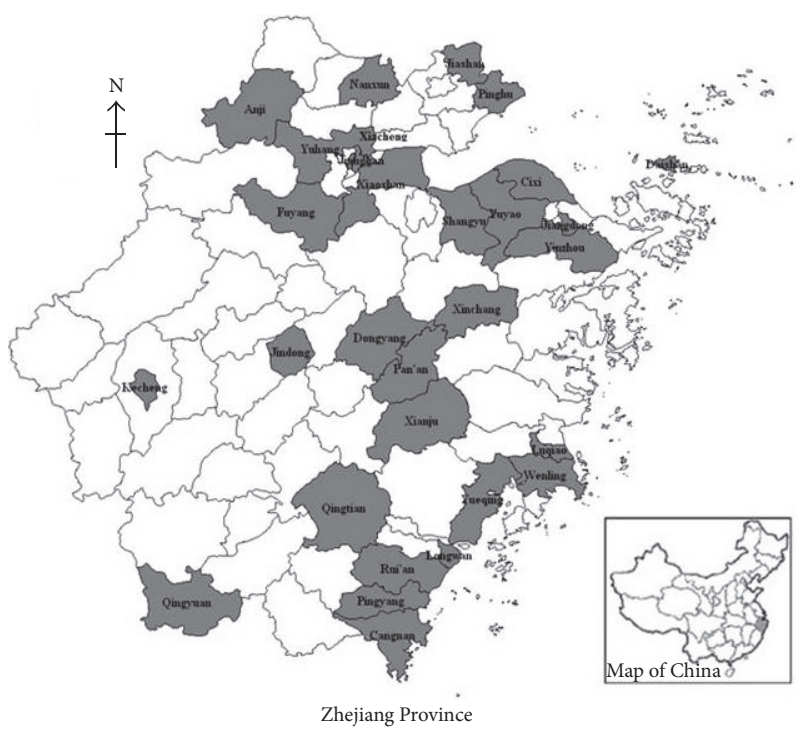

FIgure 1: Sampling counties in Zhejiang Province, China. Thirty counties (gray areas) from Zhejiang Province, in the east coastal region of China, which covers 89 counties, were selected by using a probability-proportionate-to-size sampling method.

recent data on urinary iodine and thyroid volume in Chinese schoolchildren are available. The objective of this study is to explore the reference interval for normal thyroid volumes in schoolchildren aged 8-10 years from Zhejiang Province and compare these with WHO/IGN recommended references.

\section{Subjects and Methods}

2.1. Subjects. This study was conducted in Zhejiang Province, an eastern coastal region of China that covers 89 counties. In the study, 30 counties from Zhejiang Province (Figure 1) were selected by using a probability-proportionate-to-size (PPS) sampling method; the design used current census data to provide a systematic sampling of communities based on the cumulative population. Next cluster sampling was applied to select one primary school from each selected county, and schoolchildren aged 8-10 were randomly selected in each school as investigation subjects. Data were collected from April to September 2013.

The sample size of PPS, estimated by the $N=Z_{\alpha}{ }^{2} \times$ goiter $\times(1-$ goiter $) \times($ Design effect $) / \varepsilon^{2}$ formula, assumed that $\alpha=0.05, Z_{\alpha}=1.96$, goiter $=5 \%, \varepsilon=0.02$, and design effect $=2.5$. The sample size equaled $(1.96)^{2} \times 5 \% \times 95 \% \times$ $2.5 /(0.02)^{2}=1140$, and because of loss to follow-up the investigation sample size was expanded to 1440 . Hence, each school randomly selected 48 schoolchildren aged 8-10 (24 boys and 24 girls, with 16 groups consisting of one 8-year-old, one 9-year-old, and one 10-year-old, resp.) to be investigated.

2.2. General Survey. Subjects were questioned with parental guidance and introduced to the study protocol. The questionnaire involved demographic characteristics, including age, gender, family income level, and history of disease.
2.3. Anthropometrics. The measure of height and weight was performed using WHO standard methods [21] before measurement of thyroid volume, requiring the subjects to take off shoes and belt and wear light clothes. Height measurements were precise to $0.1 \mathrm{~cm}$ and weight to $0.1 \mathrm{~kg}$. The formula of weight $(\mathrm{kg})^{0.425} \times$ height $(\mathrm{cm})^{0.725} \times 71.84 \times 10^{-4}$ [22] was used to calculate BSA $\left(\mathrm{m}^{2}\right)$.

2.4. Urinary Iodine. The instant urine samples of all subjects were collected in plastic tubes, placed at $-4^{\circ} \mathrm{C}$ before being sent to the laboratory, and analyzed for urinary iodine concentrations (UICs) by spectrophotometer method (WS/T 107-2006) [23]. According to the recommended iodine nutrition status evaluation criteria of WHO [1], severe iodine deficiency was indicated by MUIs of schoolchildren $<20 \mu \mathrm{gl}^{-1}$, moderate iodine deficiency by $20 \mu \mathrm{gl}^{-1} \leq$ MUIs $<49 \mu \mathrm{gl}^{-1}$, mild iodine deficiency by $50 \mu \mathrm{gl}^{-1} \leq$ MUIs $<99 \mu \mathrm{gl}^{-1}$, adequate iodine nutrition by $100 \mu \mathrm{gl} l^{-1} \leq$ MUIs $<199 \mu \mathrm{gl}^{-1}$, above requirements by $200 \mu \mathrm{gl}^{-1} \leq$ MUIs $<299 \mu \mathrm{gl}^{-1}$, and excessive iodine by MUIs $\geq 300 \mu \mathrm{gl}^{-1}$.

2.5. Salt Iodine. A $10 \mathrm{~g}$ edible salt sample was collected from schoolchildren's homes, stored at room temperature, and analyzed for salt iodine concentrations by colorimetric titration method (GB/T 13025.7-2012) [24]. According to the national food safety standard-iodine content of edible salt (GB 26878-2011) [25], the acceptable range of iodine content in salt is $18-33 \mathrm{mg} \mathrm{kg}^{-1}$.

2.6. Thyroid Volume. Thyroid volume was examined by a single, experienced operator, using a portable ultrasound machine (PICO, SonoAce, Korea) with a 7.5-MHZ, $60 \mathrm{~mm}$ transducer. During the examination, subjects sat straight on the chair with their neck exposed, and the operator measured the maximum width, depth, and length of the thyroid lobe from the right to left lobe and detected thyroid nodules. The thyroid capsule was not included. Thyroid volume was the sum of right and left thyroid lobe volumes; the lobe volume equals width $(\mathrm{cm}) \times$ depth $(\mathrm{cm}) \times$ length $(\mathrm{cm}) \times 0.479$ [26]

2.7. Ethics. This study was approved by the ethics committee of the Zhejiang Provincial Centre for Disease Prevention and Control (CDC). Informed written consent was obtained from the parents or guardians of the children.

2.8. Statistical Analysis. Based on the result of survey and laboratory tests, counties in which MUIs were within the range of 100 to $299 \mu \mathrm{gl}^{-1}$ and in which schoolchildren had no history of thyroid disease, had no thyroid nodules, and used the qualified iodized salt were considered eligible for inclusion in our study.

Continuous variables such as age, height, weight, and BSA, which were normally distributed according to the Shapiro-Wilk test, were described as mean \pm standard deviations (SD). UICs that were not normally distributed according to the Shapiro-Wilk test were presented as median (interquartile range [IQR]). Thyroid volume was expressed as geometric 
mean \pm SD, because logarithmically transformed values of thyroid volume were normally distributed.

Differences in original and analysis data for sex and age were analyzed by Chi-square test and by Wilcoxon test for UICs. Differences in different age or sex groups for height, weight, BSA, and thyroid volume in log scales were analyzed by one-way analysis of variance (ANOVA) or two-sample $t$ test and by Wilcoxon test or Kruskal-Wallis test for UICs. Differences between UIC groups for thyroid volume in log scales were analyzed by ANOVA.

Spearman correlation coefficient was calculated to reflect the correlation of UICs with height, weight, BSA, and thyroid volume in log scale, and the Pearson correlation coefficient was used to reflect the correlation on BSA with height and weight. Variance inflation factor was calculated to identify collinearity in the independent variables. Univariate and multivariate linear regression analyses were applied to identify the factor effect on thyroid volume in log scale. The 97th percentile (P97) of thyroid volume was calculated to compare with $\mathrm{WHO} / \mathrm{IGN}$ recommended references and other national references.

All significance tests were two-tailed, and the level of significance was $p<0.05$. Data processing and statistical calculations were performed by using SAS 9.3 software (Cary, NC, USA).

\section{Results}

3.1. General Survey. A total of 1549 schoolchildren from 30 counties in Zhejiang Province were investigated and examined. MUIs were $178.40(127.05) \mu \mathrm{gl} \mathrm{l}^{-1}$, and MUIs of 30 counties were within the range of $116.50(38.00) \mu \mathrm{gl}^{-1}$ to 285.00 (157.00) $\mu \mathrm{gl}^{-1}$. Hence, all counties were included in our study. According to the inclusion criteria, schoolchildren who had a history of thyroid disease (total 1: 1 boy and 0 girls) or thyroid nodules (total 102: 38 boys and 64 girls) or did not use the qualified iodized salt (total 162: 93 boys and 69 girls) or did not submit complete information (total 71: 39 boys and 32 girls) were excluded.

Finally, a total of 1213 schoolchildren were included in this study. These represented about 9/10,000 children in 810 -year-old groups in Zhejiang Province [27]. There were no statistically significant differences between original data and analysis data in sex and age $\left(\chi_{\text {sex }}^{2}=0.005 ; \chi_{\text {age }}^{2}=0.16\right.$; all $p>0.05)$. The sample included 610 boys and 603 girls, of which 380 were 8 -year-olds, 419 were 9 -year-olds, and 414 were 10 -year-olds. On the whole, the height of all involved schoolchildren was $134.58 \pm 7.65 \mathrm{~cm}$, weight was $30.48 \pm$ $6.70 \mathrm{~kg}$, BSA was $1.07 \pm 0.13 \mathrm{~m}^{2}$, and thyroid volume was $3.49 \pm 1.30 \mathrm{ml}$. Meanwhile, height, weight, BSA, and thyroid volume in log scale increased with an increase of age $\left(F_{\text {height }}=\right.$ $265.05, F_{\text {weight }}=107.63, F_{\mathrm{BSA}}=176.19, F_{\text {thyroid volume }}=$ 101.94 , and all $p<0.05)$. Boys had higher weight and BSA than girls $\left(t_{\text {weight }}=12.83, t_{\mathrm{BSA}}=8.74\right.$, and all $\left.p<0.05\right)$, but no differences by sex for height and thyroid volume in log scale were observed $\left(t_{\text {height }}=0.74, t_{\text {thyroid volume }}=2.25\right.$, and all $p>0.05)$. See Table 1 .
3.2. Urinary Iodine Concentrations. MUI in the involved schoolchildren was 178.30 (125.00) $\mu \mathrm{gl}^{-1}$, with the percentage of samples less than $100 \mu \mathrm{gl}^{-1}$ as $12.69 \%$ and more than $300 \mu \mathrm{gl}^{-1}$ as $15.25 \%$. MUIs in 30 counties were within the range of $115.50(39.00) \mu \mathrm{gl}^{-1}$ to $278.00(121.00) \mu \mathrm{gl}^{-1}$. There were no statistically significant differences between original data and analysis data for UICs $(Z=0.02 ; p>0.05)$. Boys had higher levels of UICs than girls $(Z=2.09$; $p<0.05)$, but differences in age for UICs were not observed $\left(\chi^{2}=0.46\right.$; $p>0.05)$. Meanwhile, there was no significant correlation in UICs with height, weight, BSA, and thyroid volume in log scale $(r=0.01,0.49,0.51$, and 0.14 ; all $p>0.05)$. See Table S1 in Supplementary Material available online at http://dx.doi.org/10.1155/2016/8079704.

3.3. Factors regarding Thyroid Volume. From the result of univariate linear regression analysis, thyroid volume in log scale was significantly associated with age, height, weight, and BSA but not with sex and UICs which was presented in Table 2.

BSA was a composite indicator calculated by height and weight. There were strong correlations in BSA with height and weight $(r=0.86$ and 0.97 ; all $p<0.05)$, and collinearity was considered in multivariate analysis (variance inflation factor $=1.98$ ). Hence, height and weight were excluded from multivariate analysis.

From the result of multivariate linear regression analysis (Table 3), only age and BSA independently were found to have a significant effect on thyroid volume in log scale after being adjusted for sex and UICs; the adjustment $R^{2}$ was 0.39 .

Geometric mean of thyroid volume increased with an increase of UICs with significant differences in the eight-yearold groups $(F=3.59 ; p<0.05)$, and there was a distinct $U$-shaped curve relationship between the geometric mean of thyroid volume and UICs at BSA of $1.2 \mathrm{~m}^{2}(F=4.14$; $p<0.05)$, which is presented in Tables 4 and S2.

3.4. Thyroid Volume. The results in Tables S3 and S4 show that age-specific P97 of thyroid volume in boys' and girls' groups averaged $32.41 \%(28.13 \%-34.88 \%)$ and $22.68 \%$ (19.68\%-24.47\%) higher, respectively, than that in the 2007 WHO/IGN recommended reference. On the other hand, BSA-specific P97 of thyroid volume in boys' and girls' groups, except the groups in which the number observed was less than 30, also averaged $38.64 \%(28.10 \%-45.31 \%)$ and $25.81 \%$ $(19.68 \%-48.80 \%)$, higher than those in the $2007 \mathrm{WHO} / \mathrm{IGN}$ recommended reference.

3.5. Compare with Other References. The age or BSA-specific median and P97 of thyroid volume by sex in our study were compared with the WHO/IGN recommended references data (Figure 2). Figure 2(a) showed that our age-specific P97 of thyroid volume in sexes combined data was very similar and nearly identical to the values found in 1993 but those in median were slightly higher than the values found in 1993. Figures 2(b) and 2(c) show that age-specific median and 
TABLE 1: Descriptive statistics of schoolchildren participating in study.

\begin{tabular}{|c|c|c|c|c|c|c|}
\hline Age (years) & Sex & $N$ & $\begin{array}{l}\text { Height }(\mathrm{cm}) \\
(\bar{x} \pm \mathrm{SD})\end{array}$ & $\begin{array}{l}\text { Weight (kg) } \\
(\bar{x} \pm \mathrm{SD})\end{array}$ & $\begin{array}{c}\mathrm{BSA}\left(\mathrm{m}^{2}\right) \\
(\bar{x} \pm \mathrm{SD})\end{array}$ & $\begin{array}{l}\text { Thyroid volume } \\
\quad(\mathrm{ml}) \\
\left(\bar{x}_{\text {Geometric }} \pm \mathrm{SD}\right)\end{array}$ \\
\hline 8 & Boy & 191 & $129.58 \pm 6.46$ & $28.32 \pm 5.54$ & $1.01 \pm 0.11$ & $3.13 \pm 1.28$ \\
\hline 8 & Girl & 189 & $128.50 \pm 5.77$ & $26.18 \pm 4.52$ & $0.97 \pm 0.09$ & $3.03 \pm 1.26$ \\
\hline 9 & Boy & 206 & $135.25 \pm 6.00$ & $30.89 \pm 5.98$ & $1.08 \pm 0.11$ & $3.53 \pm 1.25$ \\
\hline 9 & Girl & 213 & $134.27 \pm 6.43$ & $29.60 \pm 5.91$ & $1.05 \pm 0.11$ & $3.39 \pm 1.26$ \\
\hline 10 & Boy & 213 & $138.95 \pm 6.87$ & $33.96 \pm 7.67$ & $1.15 \pm 0.14$ & $3.90 \pm 1.30$ \\
\hline 10 & Girl & 201 & $140.05 \pm 6.60$ & $33.38 \pm 6.60$ & $1.14 \pm 0.12$ & $3.90 \pm 1.27$ \\
\hline 8 & & 380 & $129.04 \pm 6.14$ & $27.25 \pm 5.16$ & $0.99 \pm 0.10$ & $3.06 \pm 1.27$ \\
\hline 9 & & 419 & $134.75 \pm 6.23$ & $30.23 \pm 5.97$ & $1.07 \pm 0.11$ & $3.46 \pm 1.25$ \\
\hline \multirow[t]{3}{*}{10} & & 414 & $139.48 \pm 6.75$ & $33.68 \pm 7.17$ & $1.15 \pm 0.13$ & $3.90 \pm 1.28$ \\
\hline & Boy & 610 & $134.77 \pm 7.49$ & $31.16 \pm 6.88$ & $1.08 \pm 0.13$ & $3.53 \pm 1.30$ \\
\hline & Girl & 603 & $134.39 \pm 7.81$ & $29.79 \pm 6.45$ & $1.06 \pm 0.13$ & $3.42 \pm 1.28$ \\
\hline Total & & 1213 & $134.58 \pm 7.65$ & $30.48 \pm 6.70$ & $1.07 \pm 0.13$ & $3.49 \pm 1.30$ \\
\hline
\end{tabular}

SD: interquartile range.

TABLE 2: Univariate regression for thyroid volume in log scale as a function of sex, age, height, weight, BSA, and UICs.

\begin{tabular}{|c|c|c|c|c|c|}
\hline Variable & $\beta(95 \% \mathrm{CI})$ & Standardized estimate & Standard error & $t$ & $p$ \\
\hline Sex & $0.02(-0.01-0.05)$ & 0.04 & 0.01 & 1.50 & 0.1335 \\
\hline Age & $0.12(0.10-0.14)$ & 0.38 & 0.01 & 14.28 & $<0.0001$ \\
\hline Height & $0.01(0.01-0.02)$ & 0.42 & 0.00 & 16.07 & $<0.0001$ \\
\hline Weight & $0.02(0.02-0.02)$ & 0.44 & 0.00 & 17.11 & $<0.0001$ \\
\hline BSA & $0.91(0.81-1.00)$ & 0.47 & 0.05 & 18.30 & $<0.0001$ \\
\hline UICs & $0.000024(-0.000007-0.000055)$ & 0.04 & 0.00 & 1.49 & 0.1373 \\
\hline
\end{tabular}

BSA: body surface area; UICs: urinary iodine concentrations; CI: confidence limits.

TABLE 3: Multivariate regression for thyroid volume in log scale as a function of sex, age, BSA, and UICs.

\begin{tabular}{|c|c|c|c|c|c|}
\hline Variable & $\beta(95 \% \mathrm{CI})$ & Standardized estimate & Standard error & $t$ & $p$ \\
\hline Intercept & $-0.12(-0.27-0.03)$ & 0.00 & 0.07 & -1.59 & 0.1113 \\
\hline Sex & $0.01(-0.02-0.03)$ & 0.01 & 0.01 & 0.43 & 0.6657 \\
\hline Age & $0.07(0.05-0.08)$ & 0.20 & 0.01 & 7.32 & $<0.0001$ \\
\hline BSA & $0.72(0.60-0.82)$ & 0.37 & 0.04 & 12.84 & $<0.0001$ \\
\hline UICs & $0.00002349(-0.00000356-0.00005054)$ & 0.00 & 0.04 & 1.70 & 0.0887 \\
\hline
\end{tabular}

BSA: body surface area; UICs: urinary iodine concentrations; CI: confidence limits.

P97 of thyroid volume in boys' and girls' groups were nearly similar to the values found in 2001.

Figures 2(e) and 2(f) showed that our BSA-specific median and P97 of thyroid volume in boys' and girls' groups were similar to the values found in 2001 but were higher than those that were published in 2007. Overall, our P97 of thyroid volume was approximately $20-30 \%$ smaller than that found in 1997, irrespective of whether thyroid volume was expressed as a function of age or BSA.

The comparison of this study to the data from other national references is presented in Figures S1 and S2. Our age-specific median and P97 of thyroid volume data with sexes combined were very similar to data from United States and Iran but were about $44 \%$ in median and 20\% in $\mathrm{P} 97$ higher than those from Japan. Our age-specific P97 of thyroid volume in boys' and girls' groups was similar to data from Malaysia and Brazil but higher than that from Japan and, meanwhile, smaller than that from Turkey; in girls it was similar to that from Poland, but in boys, it was smaller than that from Poland. However, it had different patterns in median of thyroid volume data. Our age-specific median of thyroid volume in boys' and girls' groups was higher than that from Malaysia and Japan, and in boys it was similar to that from Brazil, Turkey, and Poland, but in girls, it was smaller than that from Brazil, Turkey, and Poland. Our BSA-specific median and P97 of thyroid volume data with sexes combined were, on average, about $20 \%-40 \%$ in median and $20 \%-30 \%$ in P97 higher than those from United States and Japan. Our 
TABLE 4: Comparison of geometric means of thyroid volume according to group of UICs by age.

\begin{tabular}{|c|c|c|c|c|c|c|c|c|}
\hline \multirow{3}{*}{ Age (years) } & \multicolumn{7}{|c|}{ UICs $\left(\mu \mathrm{g} \mathrm{l}^{-1}\right)$} & \\
\hline & \multicolumn{2}{|r|}{$0-99$} & \multicolumn{2}{|c|}{ 100-199 } & \multicolumn{2}{|c|}{$200-299$} & \multicolumn{2}{|r|}{$300-$} \\
\hline & $N$ & $\bar{x}_{\text {Geometric }} \pm \mathrm{SD}$ & $N$ & $\bar{x}_{\text {Geometric }} \pm \mathrm{SD}$ & $N$ & $\bar{x}_{\text {Geometric }} \pm \mathrm{SD}$ & $N$ & $\bar{x}_{\text {Geometric }} \pm \mathrm{SD}$ \\
\hline 8 & 47 & $2.89 \pm 1.26$ & 178 & $3.04 \pm 1.26$ & 97 & $3.08 \pm 1.28$ & 58 & $3.34 \pm 1.28$ \\
\hline 9 & 45 & $3.41 \pm 1.23$ & 198 & $3.45 \pm 1.24$ & 119 & $3.41 \pm 1.27$ & 57 & $3.54 \pm 1.25$ \\
\hline 10 & 62 & $4.05 \pm 1.30$ & 185 & $3.86 \pm 1.28$ & 97 & $3.91 \pm 1.28$ & 70 & $3.96 \pm 1.30$ \\
\hline
\end{tabular}

UICs: urinary iodine concentrations; SD: interquartile range.

BSA-specific median and P97 of thyroid volume in the boys' and girls' groups were similar to data from Malaysia, higher than Japan, and lower than those in Italy.

Comparisons of previous reports about thyroid volume in Zhejiang Province are shown in Figure 3. Our age-specific P97 of thyroid volume data with sexes combined was very similar to the data of Zhejiang in 2005 but higher than the data from boys and girls of Zhejiang in 2010, respectively. However, it had different patterns in median of thyroid volume data. Our age-specific median of thyroid volume data with sexes combined was lower than the data of Zhejiang in 2005 but higher than the data from boys and girls of Zhejiang in 2010, respectively. Meanwhile, our BSA-specific median and $\mathrm{P} 97$ of thyroid volume in boys' and girls' groups were also higher than the data of Zhejiang in 2010.

\section{Discussion}

In this study, the MUI in the study's schoolchildren was $178.30 \mu \mathrm{gl}^{-1}$, which was similar to the data reported in Germany (183.00 $\left.\mu \mathrm{gl}^{-1}\right)$ [28] and Bahrain (178.00 $\mathrm{gl}^{-1}$ ) [13] but higher than that in Turkey $\left(53.00 \mu \mathrm{gl}^{-1}\right)$ [29], Bangladesh $\left(73 \mu \mathrm{g}^{-1}\right)[10]$, Switzerland (115 and $\left.118.00 \mu \mathrm{g} \mathrm{l}^{-1}\right)$ $[11,13]$, Sweden $\left(125.00 \mu \mathrm{gl}^{-1}\right)$ [30], Italy $\left(125.00 \mu \mathrm{gl}^{-1}\right)[31]$, Malaysia $\left(132.80 \mu \mathrm{gl}^{-1}\right)$ [9], Netherlands $\left(154.40 \mu \mathrm{gl}^{-1}\right)$ [32], and Poland (126.60-155.10 $\mu \mathrm{gl}^{-1}$ ) [33] and less than that in South Africa $\left(191.00 \mu \mathrm{gl}^{-1}\right)$ [13], Iran $\left(212.00 \mu \mathrm{gl}^{-1}\right)$ [34], Peru (253.00 $\left.\mathrm{g} \mathrm{l}^{-1}\right)$ [13], Philippines (279.00 $\left.\mathrm{gl}^{-1}\right)$ [35], the United States $\left(282.00\right.$ and $\left.285.00 \mu \mathrm{gl}^{-1}\right)$ [10, 13], Japan $\left(281.60\right.$ and $\left.288 \mu \mathrm{gl}^{-1}\right)[13,36]$, and Brazil $\left(360.00 \mu \mathrm{gl}^{-1}\right)$ [37]. Compliance with the Universal Salt Iodization program has been mandatory since 1994 in Zhejiang Province, China, which was identified as iodine sufficient for decades in several sustained surveys from 1995 to 2011 [38]. In our study, MUIs of all 30 counties were within the range of $100-300 \mu \mathrm{gl}^{-1}$, and the percentage of total samples, which was less than $50 \mu \mathrm{gl}^{-1}$, was less than $5 \%$. Thus, most schoolchildren in our study population have spent their entire life in longstanding iodine-sufficient areas. Meanwhile, it is important to include subjects considered normal for reference, so those schoolchildren who had a history of thyroid disease or thyroid nodules or did not use the qualified iodized salt or did not submit complete information were excluded before the data analysis. Overall, we feel confident that our sample was from long-standing iodine-sufficient areas and included normal subjects.
It is well known that thyroid volume could be affected by genetic features in growth and development as well as environmental factors, including different iodine dietary intakes [13, 31, 36]. MUIs in our samples indicated iodine sufficiency, so genetic features in growth and development may have mainly contributed to the influence on thyroid volume. In our study, as in others [30, 31, 35, 36, 39], BSA and age, independently of each other, significantly positively influenced thyroid volume; these parameters are used to assess thyroid volume as adjusted predictors. However, regarding the correlation between thyroid volume and sex, UICs were not obtained, and these findings were in line with the results reported in most iodine-sufficient areas [10, $36,37]$. Interestingly, in thyroid volume, no differences in BSA and weight have been found between boys and girls, but significant difference in height suggested that height might not be an important predictor of thyroid volume compared to weight and BSA. Moreover, because only a $31 \%$ variation of thyroid volume can be determined by age and BSA on the multivariate linear regression, the major variation of thyroid volume could be explained by other factors, such as race, and significant differences in thyroid volume exist between several countries [13]. Therefore, the new international reference supports the use of a single, site-independent set of references in different countries [13]. Until now, the local thyroid volume reference data had been established in many countries [9, 11, 30, 32, 33, 36, 37]. Thus, we conducted this study to explore the references in our province.

The P97 of thyroid volume in our study of both sexes was higher than the new international reference in 2007 [1], irrespective of whether it was expressed as a function of age and BSA, and similar to the reference in 1993 [19] and 2001 [20] but lower than the reference in 1997 [6], when the data had a systematic measures bias that resulted in higher values, which were corrected to issue the reference in 2001 [20]. The larger thyroid volume was probably not determined by lower MUIs than those (MUIs: $203 \mu \mathrm{gl}^{-1}$ ) [13] in the new international reference population because there is no overall correlation between thyroid volume and UICs during times of iodine sufficiency $[13,18]$, which was consistent with the results of our study, as mentioned earlier, although with a slight difference between the two at 8 years of age and $1.2 \mathrm{~m}^{2}$ of BSA.

Two earlier studies reported thyroid volume in schoolchildren of Zhejiang Province [17, 18], which provided earlier data for this study, although there were some limitations 


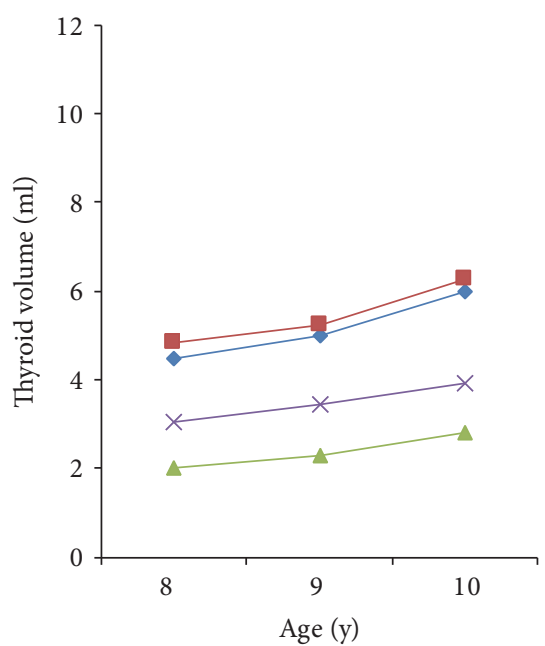

— 1993 WHO sexes combined P97

- - This study's sexes combined P97

- 1993 WHO sexes combined median

$\times$ This study's sexes combined median

(a)

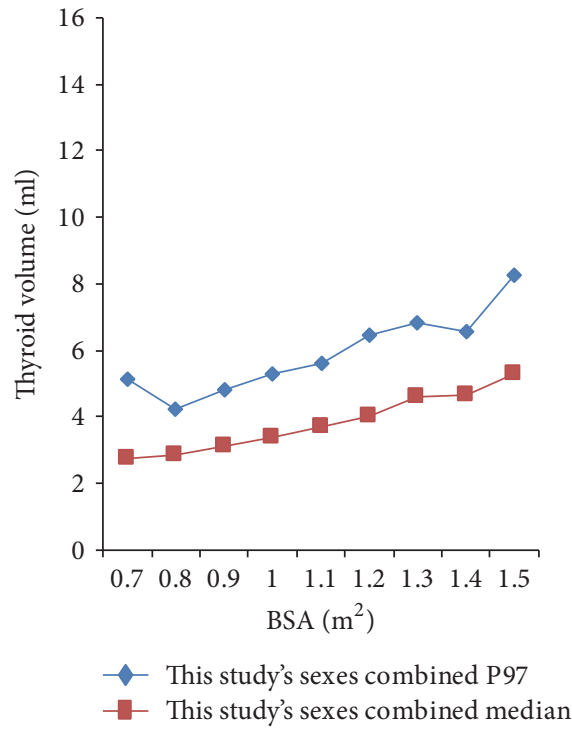

(d)

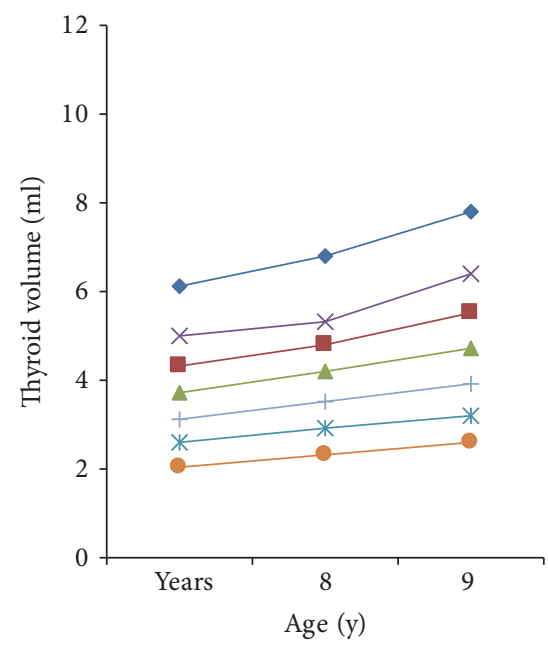

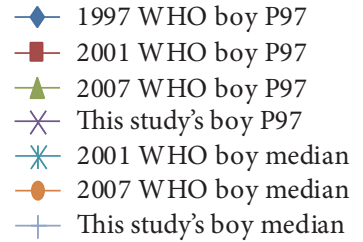

(b)

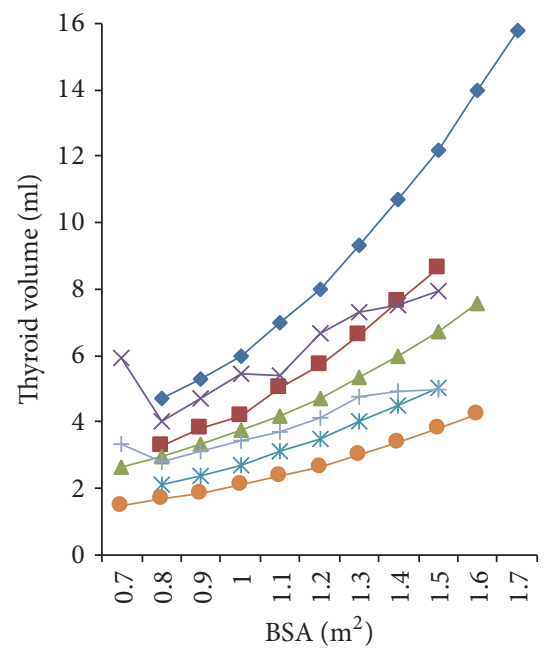

-1997 WHO boy P97

- 2001 WHO boy P97

- 2007 WHO boy P97

$\times$ This study's boy P97

* 2001 WHO boy median

- 2007 WHO boy median

- This study's boy median

(e)

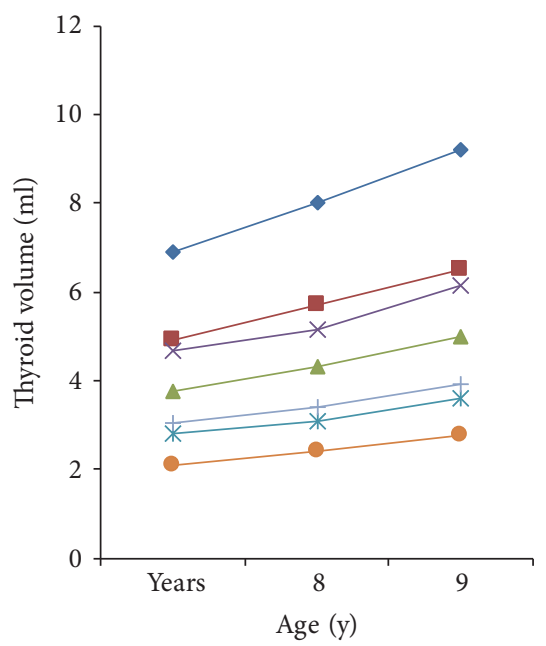

$\smile \_1997$ WHO girl P97

- 2001 WHO girl P97

ـ 2007 WHO girl P97

$\times \quad$ This study's girl P97

* $2001 \mathrm{WHO}$ girl median

- 2007 WHO girl median

+ This study's girl median

(c)

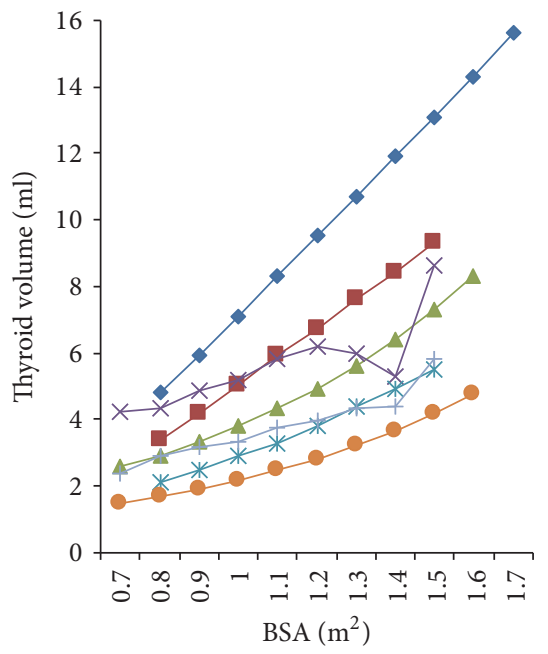

- 1997 WHO girl P97

- 2001 WHO girl P97

- 2007 WHO girl P97

$\times \quad$ This study's girl P97

* 2001 WHO girl median

- 2007 WHO girl median

+ This study's girl median

(f)

FIGURE 2: Comparison of median and P97 of thyroid volume between this study and WHO/IGN recommended references by age and BSA. (a), (b), and (c) show reports published from 1993 to 2007 [1, 6, 19, 20]; (d), (e), and (f) show reports published from 1997 to 2007 [1, 6, 20].

in those studies. Compared with the data from the study in 2005 [17], the age-specific P97 of thyroid volume in our study was very similar to those reference values, indicating the reproducibility of the results. Unfortunately, the growth and development factors of children were not measured in the study of 2005, so the BSA-specific P97 could not be presented. The data from the study in 2010 [18] was applied by polynomial regression to fit the data, but this study was based on a relatively small number of observations with a larger age range. 

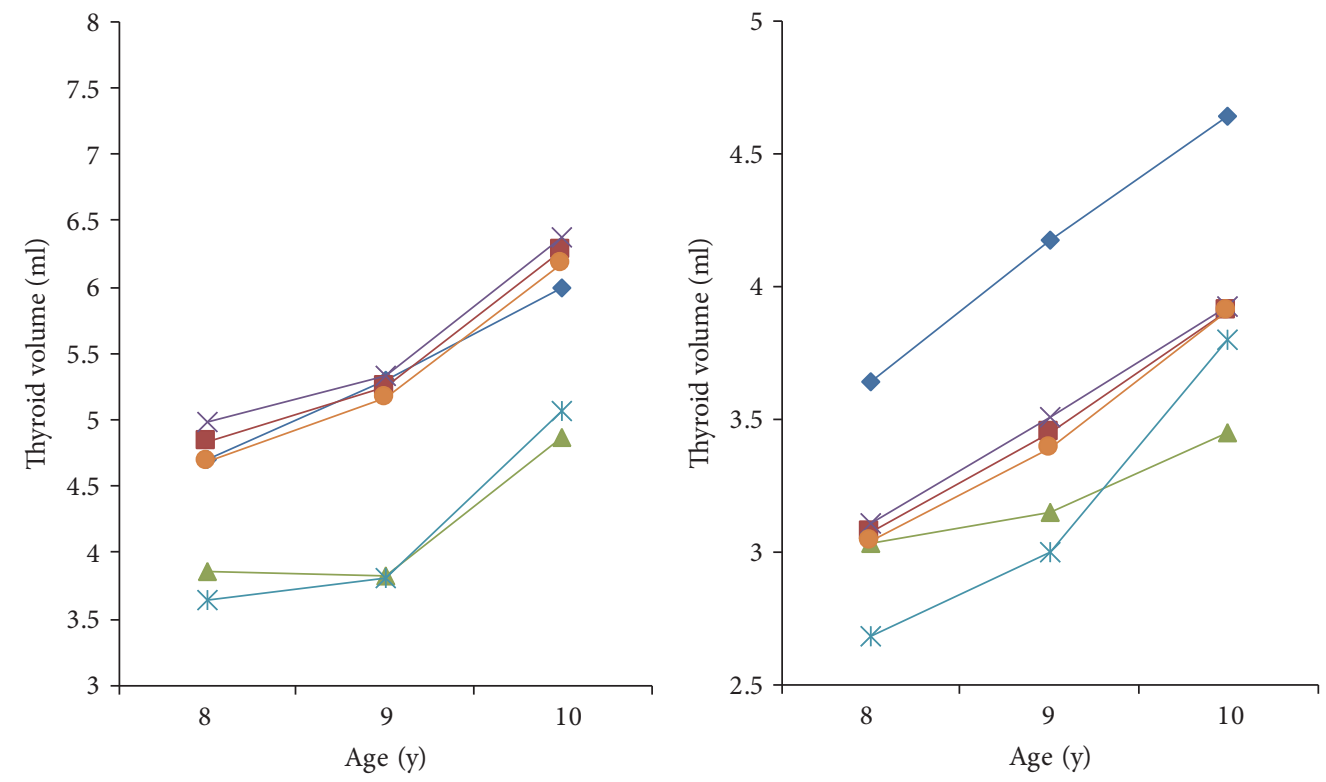

- Zhejiang sexes combined 2005 P97
- This study's sexes combined P97
- Zhejiang boy 2010 P97

(a)

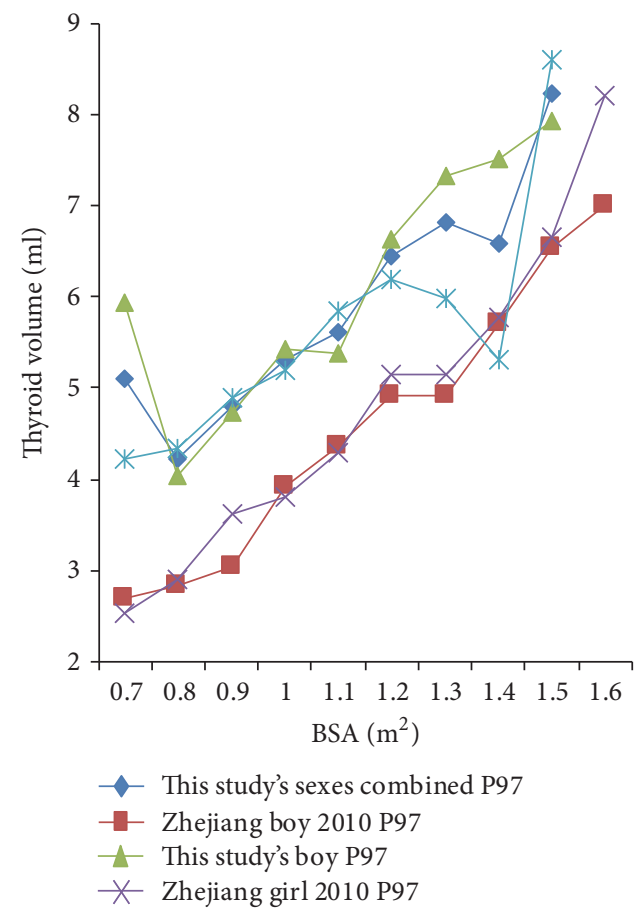

(c) $\neg$ Zhejiang sexes combined 2005 median

-1- This study's sexes combined median

- Zhejiang boy 2010 median

$\star$ This study's boy median

(b)

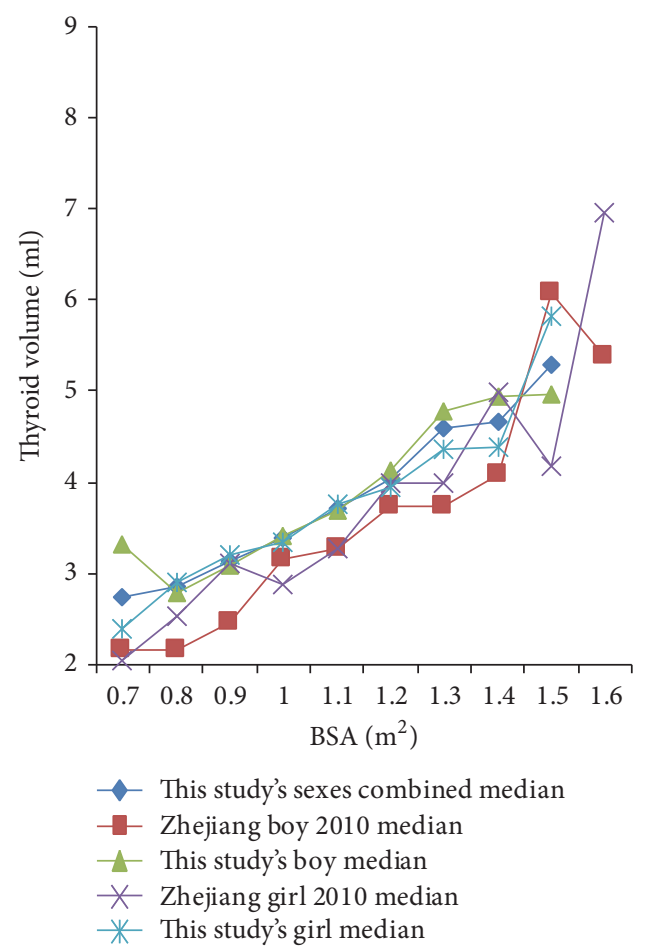

(d)

FIgURE 3: Comparison of median and P97 of thyroid volume between this study and previous reports in Zhejiang Province, China, by age and BSA. (a) and (b) show studies carried out from 2005 to 2013 [17, 18]; (c) and (d) show studies carried out from 2010 to 2013 [18]. 
In the comparison of thyroid volume in different countries, as in the results of Zimmermann et al. [13], there were significant differences between countries in age and BSAadjusted P97 of thyroid volume. At the age-specific P97, our values were similar to the data reported in Malaysia [9], the United States [10], Iran [34], and Poland [33] in girls from iodine-sufficient areas and the data reported in Brazil [37] from iodine-excessive areas but higher than those in Japan [36] from iodine-sufficient areas and lower than those in Turkey [29] and Poland [33] in boys from iodine-sufficient areas. At the BSA-specific P97, our values were similar to the data reported in Malaysia [9] but higher than those in Japan [36] and United States [10] and lower than those in Italy [31] from iodine-sufficient areas. Overall, the P97 of thyroid volume in our study by age and BSA was similar to those in Malaysia [9], which is located in Southeast Asia near the southern area of China, and it had almost the same age composition as our two samples. However, our P97 values were far higher than those in Japan [36], near the northeast area of China, which is a special one with small thyroid gland volume and high iodine excretion. Meanwhile, our P97 values were lower than those in European counties such as Turkey [29], whereas iodine deficiency control programs have not been successful up to recent years, and the higher values may reflect moderate iodine deficiency (MUIs: $53 \mu \mathrm{gl}^{-1}$ ), and as in Poland [33] and Italy [31], whereas these differences could be attributed to the differences in body size or ethnicity in these samples.

There were some limitations in this study. First, precision was not estimated by examining thyroid volume of the same subjects twice, although thyroid volume in our study was examined by a single experienced operator. Second, it is difficult to calculate the interobserver variation with the new international reference of 2007 [1], which could contribute partially to the difference between two samples. Third, the sample size of some BSA-specific groups of children, especially for $0.7,1.4$, and $1.5 \mathrm{~m}^{2}$ groups, is not enough to make final decision.

\section{Conclusions}

Our data suggested that the iodine nutritional status in Zhejiang Province was at an adequate level. Thyroid volume in our study shows a significant correlation with age and anthropometric measurements, independent of each other. The P97 of thyroid volume in our study was larger generally than the new international reference and similar to the previous $\mathrm{WHO} / \mathrm{IGN}$ reference, which on the one hand appears acceptable for local use. Because of the limitations mentioned earlier, another study should be performed to complete the regional reference.

\section{Disclosure}

The funds had no role in the design, analysis, or writing of this article.

\section{Competing Interests}

None of the authors has a conflict of interests.

\section{Acknowledgments}

This research was carried out with financial support from the National Natural Science Foundation of China (81502786), Zhejiang Province Science and Technology Fund (2009C03010-1), and Zhejiang Province Medical and Technology Fund (2015KYA053). The authors thank the staff of the Center for Disease Control and Prevention in the 30 sampling counties of Zhejiang Province, China, who collected the epidemiological data. The authors particularly thank all the participants and their families for their contributions and support.

\section{References}

[1] WHO/UNICEF/ICCIDD, Assessment of Iodine Deficiency Disorders and Monitoring their Elimination: A Guide for Program Managers, WHO, Geneva, Switzerland, 2007.

[2] S. R. Brahmbhatt, R. M. Brahmbhatt, and S. C. Boyages, "Thyroid ultrasound is the best prevalence indicator for assessment of iodine deficiency disorders: a study in rural/tribal schoolchildren from Gujarat (Western India)," European Journal of Endocrinology, vol. 143, no. 1, pp. 37-46, 2000.

[3] S. Peterson, A. Sanga, H. Eklöf et al., "Classification of thyroid size by palpation and ultrasonography in field surveys," The Lancet, vol. 355, no. 9198, pp. 106-110, 2000.

[4] S. Kaniuka-Jakubowska, M. Piskunowicz, A. Zapasnik et al., "US not bright but right method of thyroid volume estimation even in large and substernal extended goitres. Comparison of US and three methods of CT thyroid evaluation-Prospective Study," Clinical Endocrinology, vol. 83, no. 3, pp. 412-419, 2015.

[5] R. Gutekunst and H. Martin-Teichert, "Requirements for goiter surveys and the determination of thyroid size," in Iodine Deficiency in Europe, F. Delange, J. T. Dunn, and D. Glinoer, Eds., vol. 241 of NATO ASI Series, pp. 109-118, Springer, Boston, Mass, USA, 1993.

[6] WHO/UNICEF/ICCIDD, "Recommended normative values for thyroid volume in children aged 6-15 years. World Health Organization \& International Council for Control of Iodine Deficiency Disorders," Bulletin of the World Health Organization, vol. 75, no. 2, pp. 95-97, 1997.

[7] F. Delange, G. Benker, P. Caron et al., "Thyroid volume and urinary iodine in European schoolchildren: standardization of values for assessment of iodine deficiency," European Journal of Endocrinology, vol. 136, no. 2, pp. 180-187, 1997.

[8] F. Delange, "What do we call a goiter?" European Journal of Endocrinology, vol. 140, no. 6, pp. 486-488, 1999.

[9] L. C. Foo, A. Zulfiqar, M. Nafikudin, M. T. Fadzil, and A. S. A. Asmah, "Local versus WHO/International Council for Control of Iodine Deficiency Disorders-recommended thyroid volume reference in the assessment of iodine deficiency disorders," European Journal of Endocrinology, vol. 140, no. 6, pp. 491-497, 1999.

[10] F. Xu, K. Sullivan, R. Houston, J. Zhao, W. May, and G. Maberly, "Thyroid volumes in US and Bangladeshi schoolchildren: comparison with European schoolchildren," European Journal of Endocrinology, vol. 140, no. 6, pp. 498-504, 1999. 
[11] S. Y. Hess and M. B. Zimmermann, "Thyroid volumes in a national sample of iodine-sufficient Swiss school children: comparison with the World Health Organization/International Council for the Control of Iodine Deficiency Disorders normative thyroid volume criteria," European Journal of Endocrinology, vol. 142, no. 6, pp. 599-603, 2000.

[12] M. B. Zimmermann, L. Molinari, M. Spehl et al., "Toward a consensus on reference values for thyroid volume in iodinereplete schoolchildren: results of a workshop on interobserver and inter-equipment variation in sonographic measurement of thyroid volume," European Journal of Endocrinology, vol. 144, no. 3, pp. 213-220, 2001.

[13] M. B. Zimmermann, S. Y. Hess, L. Molinari et al., "New reference values for thyroid volume by ultrasound in iodinesufficient schoolchildren: a World Health Organization/Nutrition for Health and Development Iodine Deficiency Study Group Report," The American Journal of Clinical Nutrition, vol. 79, no. 2, pp. 231-237, 2004.

[14] P. Liu, X. Su, H. Shen et al., "National iodine deficiency disorders: an analysis of surveillance data in 2011," Chinese Journal of Endemiology, vol. 34, no. 3, pp. 181-185, 2015.

[15] S. Liu, "The monitoring results of iodine deficiency disorders from 2011 and 2014, in China," Chinese Journal of Endemiology, vol. 34, no. 9, pp. 632-635, 2015.

[16] MOHC, Diagnostic Criteria for Endemic Goiter. WS 276-2007, China Criterria Publishing House, Beijing, China, 2008.

[17] J. Zhou, X. Huang, W. Zhu et al., "Study on the upper limit and its revision method of normal thyroid volume of children of 810 years-old in Zhejiang Province," Wei Sheng Yan Jiu, vol. 36, no. 4, pp. 517-519, 2007.

[18] Y. Zou, G. Ding, X. Lou et al., "Factors influencing thyroid volume in Chinese children," European Journal of Clinical Nutrition, vol. 67, no. 11, pp. 1138-1141, 2013.

[19] World Health Organization, International Council for Control of Iodine Deficiency Disorders, and UNICEF, Indicators for Assessing Iodine Deficiency Disorders and Their Control Through Salt Iodization, 1993.

[20] M. Zimmermann, L. Molinari, M. Spehl et al., "Updated provisional WHO/ICCIDD reference values for sonographic thyroid volume in iodine-replete school-age children," IDD Newsletter, vol. 17, no. 1, p. 12, 2001.

[21] W. E. Committee, "Physical status: the use and interpretation of anthropometry," WHO Technical Report Series, vol. 854, no. 121, p. $55,1995$.

[22] M. Zimmermann, A. Saad, S. Hess, T. Torresani, and N. Chaouki, "Thyroid ultrasound compared with World Health Organization 1960 and 1994 palpation criteria for determination of goiter prevalence in regions of mild and severe iodine deficiency," European Journal of Endocrinology, vol. 143, no. 6, pp. 727-731, 2000.

[23] S. Q. S. Bureau, Method for Determination of Iodine in Urine by $\mathrm{As}^{3+}-\mathrm{Ce}^{4+}$ Catalytic Spectrophotometry. WS/T 107-2006, China Criterria Publishing House, Beijing, China, 2006.

[24] S. Q. S. Bureau, General Test Method in Salt IndustryDetermination of Iodine.GB/T 13025.7-2012, China Criterria Publishing House, Beijing, China, 2012.

[25] MOHC, Iodine Content in Edible Salt. GB 26878-2011, China Criterria Publishing House, Beijing, China, 2011.

[26] J. Brunn, U. Block, and G. Ruf, "Volumetric analysis of thyroid lobes by real-time ultrasound," Deutsche Medizinische Wochenschrift, vol. 106, no. 41, pp. 1338-1340, 1981.
[27] O. O. T. S. C. I. Z. Province, 2010 Zhejiang Census Data, Zhejiang Gongshang University Press, Hangzhou, China, 2011.

[28] J. Rendl, N. Juhran, and C. Reiners, "Thyroid volumes and urinary iodine in German school children," Experimental and Clinical Endocrinology and Diabetes, vol. 109, no. 1, pp. 8-12, 2001.

[29] S. Darcan, P. Unak, O. Yalman et al., "Determination of iodine concentration in urine by isotope dilution analysis and thyroid volume of school children in the west coast of Turkey after mandatory salt iodization," Clinical Endocrinology, vol. 63, no. 5, pp. 543-548, 2005.

[30] H. Filipsson Nyström, M. Andersson, G. Berg et al., “Thyroid volume in Swedish school children: a national, stratified, population-based survey," European Journal of Clinical Nutrition, vol. 64, no. 11, pp. 1289-1295, 2010.

[31] D. Bonofiglio, S. Catalano, A. Perri et al., "Beneficial effects of iodized salt prophylaxis on thyroid volume in an iodine deficient area of southern Italy," Clinical Endocrinology, vol. 71, no. 1, pp. 124-129, 2009.

[32] W. M. Wiersinga, J. Podoba, M. Srbecky, M. van Vessem, H. C. van Beeren, and M. C. Platvoet-ter Schiphorst, "A survey of iodine intake and thyroid volume in Dutch schoolchildren: reference values in an iodine-sufficient area and the effect of puberty," European Journal of Endocrinology, vol. 144, no. 6, pp. 595-611, 2001.

[33] Z. Szybiński, M. Trofimiuk-Müldner, M. Buziak-Bereza, L. Walczycka, and A. Hubalewska-Dydejczyk, "Reference values for thyroid volume established by ultrasound in Polish schoolchildren," Endokrynologia Polska, vol. 63, no. 2, pp. 104109, 2012.

[34] F. Azizi, H. Delshad, and Y. Mehrabi, "Thyroid volumes in schoolchildren of Tehran: comparison with European schoolchildren," Journal of Endocrinological Investigation, vol. 24, no. 10, pp. 756-762, 2001.

[35] B. K. Kim, Y. S. Choi, C. H. Oak et al., "Determination of thyroid volume by ultrasonography among schoolchildren in Philippines," International Journal of Endocrinology, vol. 2012, Article ID 387971, 6 pages, 2012.

[36] Y. Fuse, N. Saito, T. Tsuchiya, Y. Shishiba, and M. Irie, "Smaller thyroid gland volume with high urinary iodine excretion in Japanese schoolchildren: normative reference values in an iodine-sufficient area and comparison with the WHO/ICCIDD reference," Thyroid, vol. 17, no. 2, pp. 145-155, 2007.

[37] A. Rossi, E. Tomimori, R. Camargo, and G. Medeiros-Neto, "Determination of thyroid volume by sonography in healthy Brazilian schoolchildren," Journal of Clinical Ultrasound, vol. 30, no. 4, pp. 226-231, 2002.

[38] W. Zhu, J. Zhou, G. Mao, and Z. Mo, "Analysis of iodine deficiency disorders surveillance of Zhejiang Province in 2011," Zhejiang Preventive Medicine, vol. 24, no. 8, pp. 10-12, 2012.

[39] J. Svensson, P. E. Nilsson, C. Olsson, J.-Å. Nilsson, B. Lindberg, and S.-A. Ivarsson, "Interpretation of normative thyroid volumes in children and adolescents: is there a need for a multivariate model?” Thyroid, vol. 14, no. 7, pp. 536-543, 2004. 


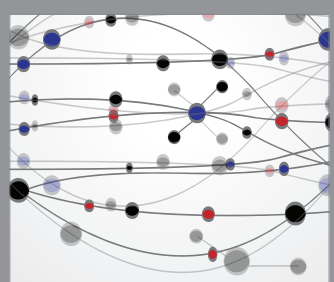

The Scientific World Journal
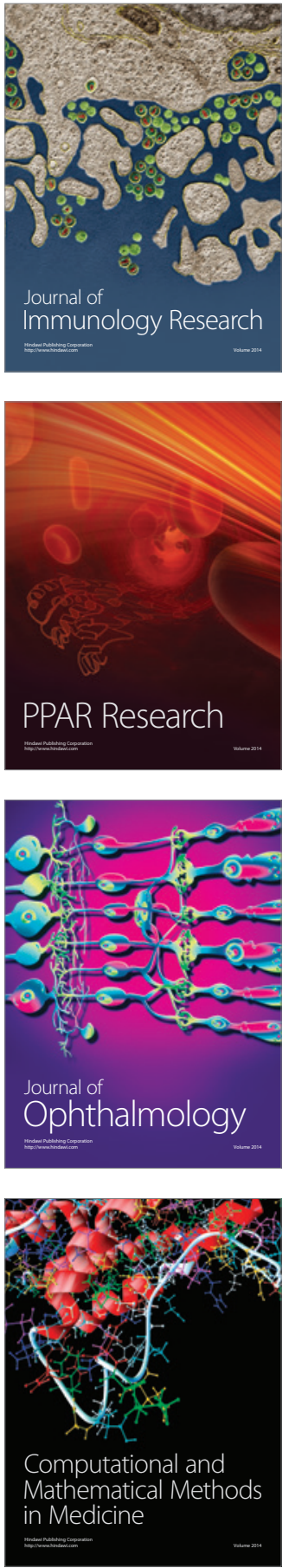

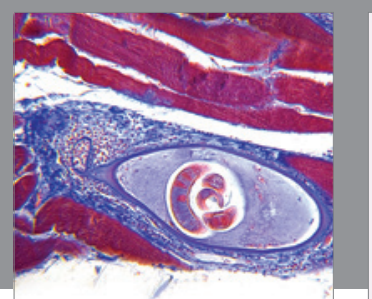

Gastroenterology Research and Practice

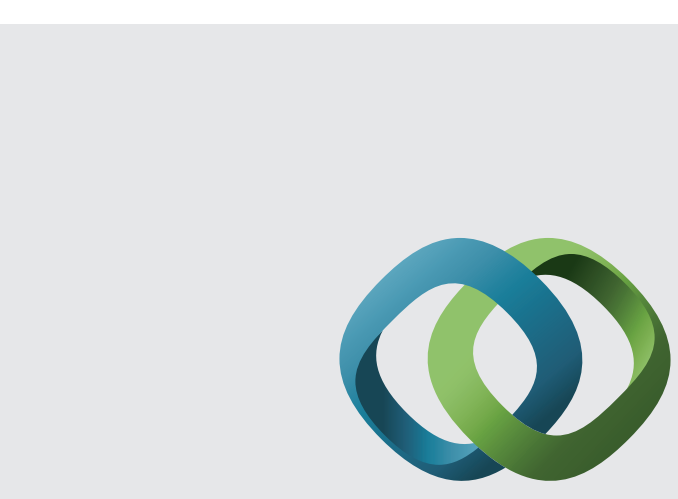

\section{Hindawi}

Submit your manuscripts at

http://www.hindawi.com
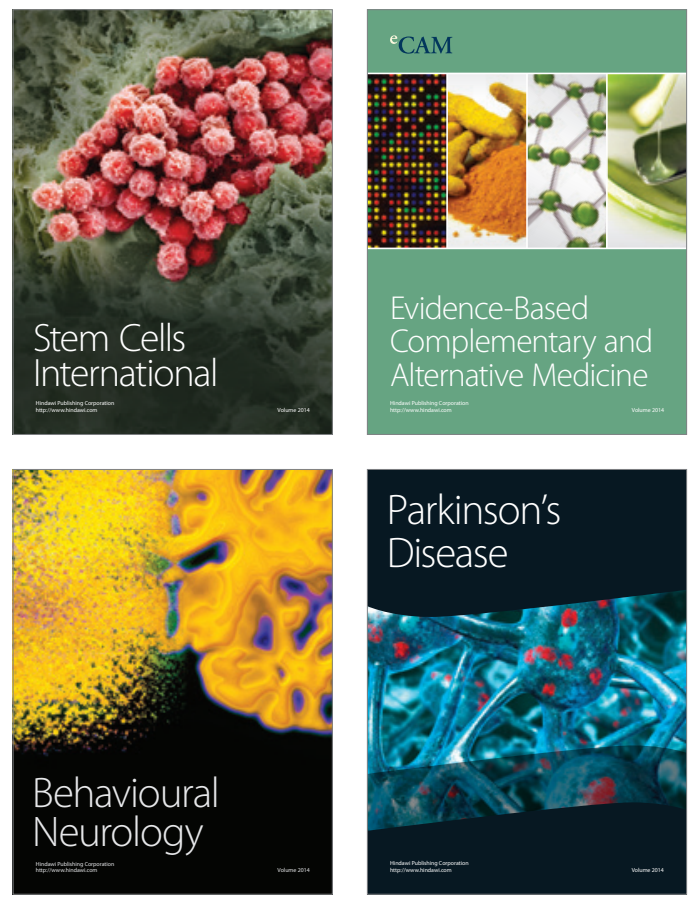
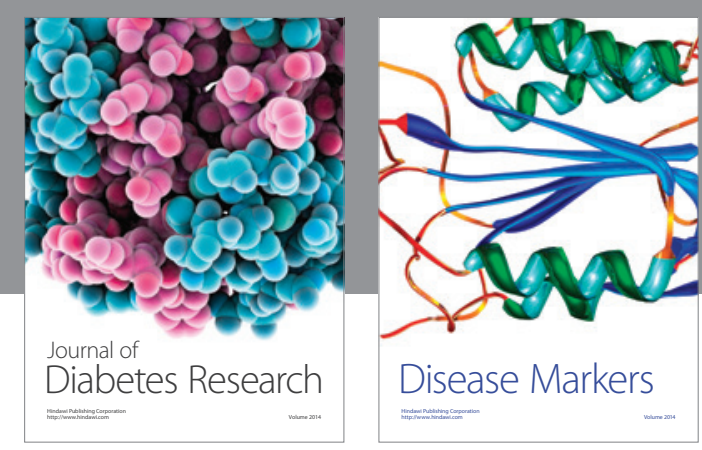

Disease Markers
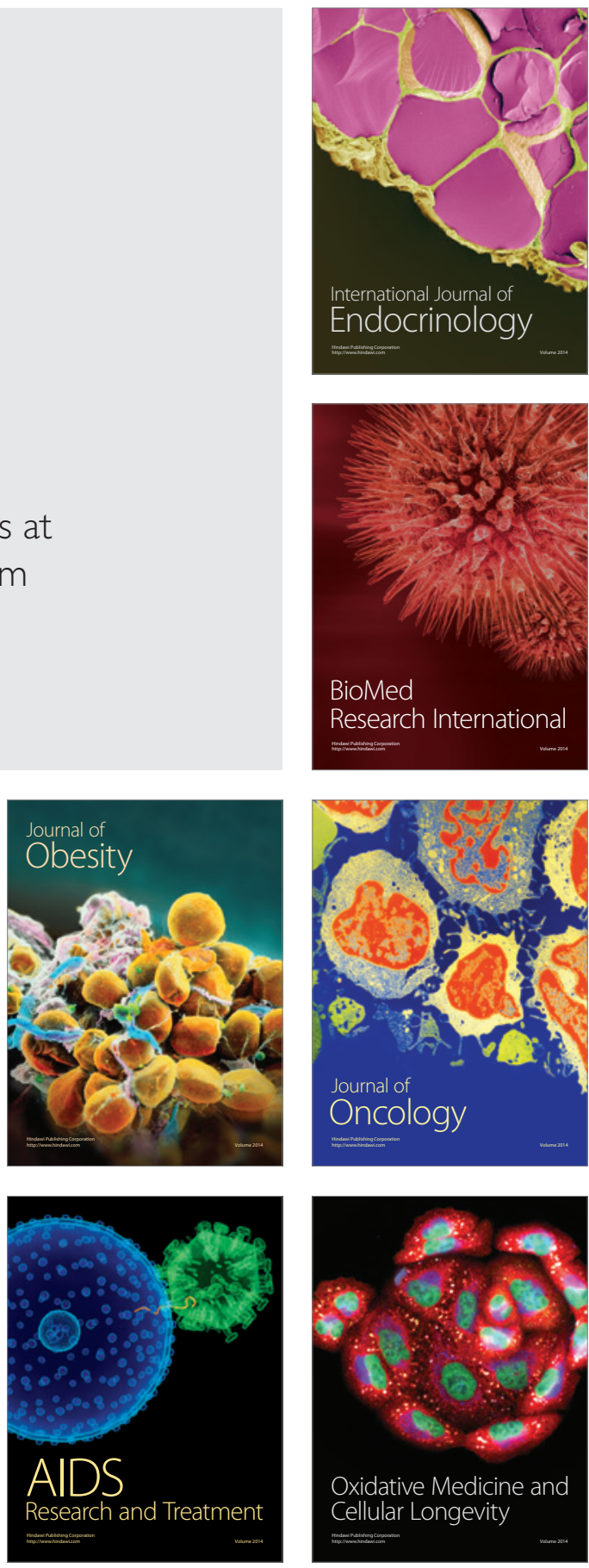